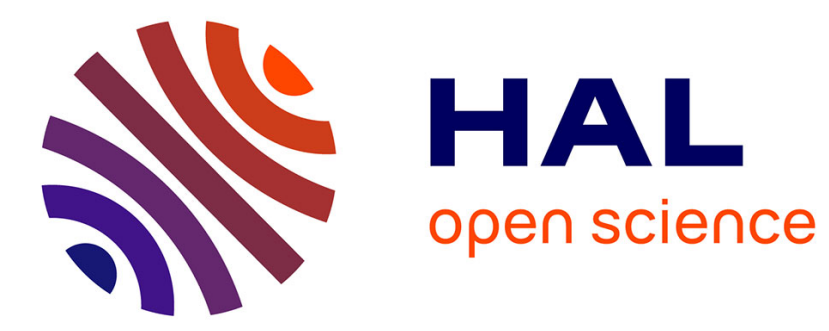

\title{
Speculative Attack and Informational Structure: An Experimental Study \\ Camille Cornand
}

\section{To cite this version:}

Camille Cornand. Speculative Attack and Informational Structure: An Experimental Study. 2004. halshs-00180118

\section{HAL Id: halshs-00180118 \\ https://shs.hal.science/halshs-00180118}

Submitted on 17 Oct 2007

HAL is a multi-disciplinary open access archive for the deposit and dissemination of scientific research documents, whether they are published or not. The documents may come from teaching and research institutions in France or abroad, or from public or private research centers.
L'archive ouverte pluridisciplinaire HAL, est destinée au dépôt et à la diffusion de documents scientifiques de niveau recherche, publiés ou non, émanant des établissements d'enseignement et de recherche français ou étrangers, des laboratoires publics ou privés. 
W.P. 04-07

\title{
Speculative Attack and Informational Structure: An Experimental Study
}

\author{
Camille Cornand
}

Juillet 2004

GATE Groupe d'Analyse et de Théorie Économique UMR 5824 du CNRS

93 chemin des Mouilles - 69130 Écully - France

B.P. 167 - 69131 Écully Cedex

Tél. +33 (0)4 72866060 - Fax +33 (0)4 72866090

Messagerie électronique gate@gate.cnrs.fr Serveur Web : www.gate.cnrs.fr 


\section{Speculative Attack and Informational Structure: \\ An Experimental Study}

Camille Cornand ${ }^{1}$

February 12, 2004

Titre Français : Attaque spéculative et structure informationnelle : une étude expérimentale

\section{RESUME :}

Ce papier s'intéresse à la question de la déstabilisation d'une économie par des signaux publics dans un contexte où les informations sont de nature différente. Nous présentons une expérience sur le jeu de l'attaque spéculative de Morris et Shin (1998). Notre objectif est double: (i) évaluer si l'information publique déstabilise l'économie dans un contexte où les signaux sont de nature différente; et (ii) élargir les résultats de Heinemann, Nagel et Ockenfels (2002). Notre étude suggère que dans les sessions avec signaux commun et privé, le fait que le signal joue un rôle focal améliore le bien être de la banque centrale : sa présence che reduit la probabilite de crise et acccôt sa prévisibilité. En ternes de politique économique, la banque centrale a plus de contrôle sur les croyances des spéculateurs si elle fournit au marché un signal clair, lorsque celui-ci reçoit aussi des signaux privés.

MOTS-CLES : Attaques spéculatives - Information privée - Information publique.

\section{ABSTRACT:}

This paper addresses the question whether public information destabilises the economy in the context of signals of different nature. We present an experiment on the speculative attack game of Morris and Shin (1998). Our objective is double: (i) evaluating whether public information destabilises the economy in a context of signals of different nature; and (ii) enlarging the results of Heinemann, Nagel and Ockenfels (2002). Our evidence suggests that in sessions with both private and common signals, the fact that the public signal plays a focal role enhances the central bank's welfare: it reduces the probability of crisis and increases its predictability. In tems of econs traders if it discloses one clear signal when agents also get private information from other sources.

KEY-WORDS: Speculative attacks, Private information, Public Information.

JEL CLASSIFICATION: F3, C9.

${ }^{1}$ Camille Cornand, Lyon 2 University, GATE - CNRS, cornand@gate.cnrs.fr. I am thankful to Frank Heinemann for very helpful comments, to Jean-Pierre Allegret and Nadège Marchand for useful discussions, and to Romain Zeiliger for programing Regate. All remaining errors are my own responsibility. I also acknowledge the financial support of the Money Department of Lyon 2 University. Finally, I thank the students for their participation to the experimen.

\section{Introduction}

The policy response to the recent turbulence in international financial markets has been to call for increased transparency through information disclosures from governments and other official bodies as well as from the major market participants (International Monetary Fund, 1998 and Basel Committee on Banking Supervision, 1999). Increased transparency could prevent from speculative crashes and, simultaneously, make sure that unsustainable pegs be corrected early enough. Indeed, public information is expected to reduce efficiency losses stemming from coordination failures: since market expectations are influenced by central bank disclosures - and in return have an impact on financial variables -, monetary policy is more effective if it can coordinate market expectations. However, there exists a current discussion on the optimal modes of information disclosure. This paper thus addresses the question whether public information destabilises the economy in a context of signals of different nature.

Theoretically, the impact of public information is large: public information is extremely effective at influencing decisions and coordinating actions. There is even a danger arising from the fact that it is too effective at doing so. For example, the model of Morris and Shin (2002) predicts that agents follow more public than private information when signals are of the same precision. Agents overreact to public information and thereby magnify the damage done by any noise.

Empirically, the impact of public and private information on the coordination of agents has been studied by experimental economics. While Cabrales, Nagel and Armenter (2002) wondered about which equilibrium prevails if agents possess either private or public information, Heinemann, Nagel and Ockenfels (2002) also compare the individual impact of such informational structures on the decision making process. They present an experiment which imitates a speculative attack model à la Obstfeld (1996) and Morris and Shin (1998) and show that the predictability of an attack is slightly higher in public information than private information, but the prior probability is also higher in public information. If this experiment tends to validate the global game theory, it however appears that the destabilising effects of public information, linked with the existence of multiple equilibria, can be less severe than what is predicted theoretically. The rationale for the fact that the experiment shows that agents' behaviour is very similar in both informational contexts (sessions in public information and sessions in private information) is the following (Heinemann, 2002). On the one hand, transparency increases predictability and reduces efficiency losses linked to non- 
coordinated activities; on the other, public information increases the probability of an attack by reinforcing the agents' beliefs in the capacity of the group of coordinating on the efficient strategy. This suggests that public information does not necessarily lead to common knowledge: even if public announcements should theoretically lead to higher order beliefs close to common knowledge, differences in the treatment of public information seem to create sufficient private beliefs to avoid self-fulfilling beliefs equilibria and thus common knowledge.

Heinemann, Nagel and Ockenfels (2002) consider two informational treatments in the context of the speculative attack game: public information on the fundamental state of the economy on the one hand, and private information on the other. In this paper, we propose to analyse the impact of public information on how agents coordinate in presence of both public and private signals. More precisely, does public information have the same coordination power when agents also get private signals? To answer such a question, we analyse in details two different informational treatments: simultaneous noisy public and private informational signals and two noisy public information signals (i.e. benchmark case). This experimental study aims at drawing a comparison between those two treatments to catch the impact of public information. Therefore, it has two main objectives: to empirically evaluate the relevance of the informational structure during a speculative attack with an experiment and to enlarge the results acquired by Heinemann, Nagel and Ockenfels (2002) (HNO, 2002).

We find that there is a significant difference between the two treatments. Our evidence suggests that in public and private information treatment, the public signal always plays a more important role in the decision taken by agents: success and thus probability of an attack clearly more depend on the public signal. The main result is that the probability of a crisis is always smaller and the predictability better achieved in simultaneous private and public signals than in otherwise equal treatment with two common signals. However, it is not clear in which of the two treatments coordination is better achieved. On the one hand, the existence of a focal point in public and private information treatment should reinforce the capacity of a group to coordinate; on the other hand, the presence of private information avoids overreaction linked to self-fulfilling beliefs in total common information games. In terms of economic policy, our result suggests that the central bank has more control on the beliefs of traders if it discloses one clear signal, when agents additionally get private information from other sources.

The remaining of this paper is structured as follows. Section 2 sums up the main theoretical results about the role of the informational structure in speculative attack games. Section 3 lays out the experimental design based on HNO (2002). Section 4 details the results of the experiment, in terms of agents' decision, probability of an attack, predictability of an attack, coordination and welfare losses. Section 5 compares our results with the study by HNO (2002) and section 6 concludes the paper.

\section{Theoretical predictions}

The possibility to analyse the role of information disclosure is relatively recent. The literature on "global games" shows that there can exist a unique equilibrium in a framework where multiple equilibria would exist in a situation of common knowledge on economic fundamentals. The existence of the unique equilibrium in such games allows studying the impact of information with the means of comparative statics. After rapidly presenting the reduced form of the speculative attack game, we give the theoretical results under different informational assumptions.

\subsection{The speculative attack game as a coordination game in incomplete information}

We describe a very simple version of the model of Morris and Shin (1998), inspired from Heinemann (2002).

The game comprehends an infinite number of small traders $i \in[0,1]$ who decide whether to attack or not. The fundamental state is noted $Y$. A higher $Y$ is interpreted as a better state of the economy. If the proportion of traders who attack exceeds a hurdle function $a(Y)\left(a^{\prime}<0\right)$, the attack succeeds and each attacking agent receives a reward equal to Y. However, if the attack fails, attacking agents get 0 . Whatever happens, non-attacking agents always get a reward equal to $T$.

\subsection{Predictions with respect to the informational structure of the game}

We give the main theoretical predictions of this game under different informational structures: public information, private information, and, finally, simultaneous public and private signals.

2.2.1. Public information

In the second-generation models with common knowledge on economic fundamentals $Y$, coordination is due to a sunspot (i.e. a public announcement), which coordinates the actions of all the speculators. A canonical model is Obstfeld (1996), in which there exist three zones of fundamental states (as shown in Figure 1):

- if $Y<T$, the fundamental state is so good that no attack can occur;

- if $Y>\bar{Y}$, the fundamental state is so bad that there will be a devaluation for sure; 
- if $T<Y<\bar{Y}$, there exist two pure strategy equilibria: all the agents attack or none of them attack.

In such a context, the simple fact that a signal be common knowledge coordinates agents' on an equilibrium (rather than another). There is an indetermination in the theory, which is linked to the coordinating power of public information. Beliefs are self-fulfilling and the result is linked to a change in anticipations and not directly to fundamentals in the sense that worse fundamentals are more likely to conduct to the bad equilibrium in the zone of indeterminacy. We call this situation the Common Information game (CI).

Such an analysis raises doubts about the advantages of public information disclosure as advocated by International Financial Institutions. The existence of multiple equilibria doesn't allow for any policy prescription.

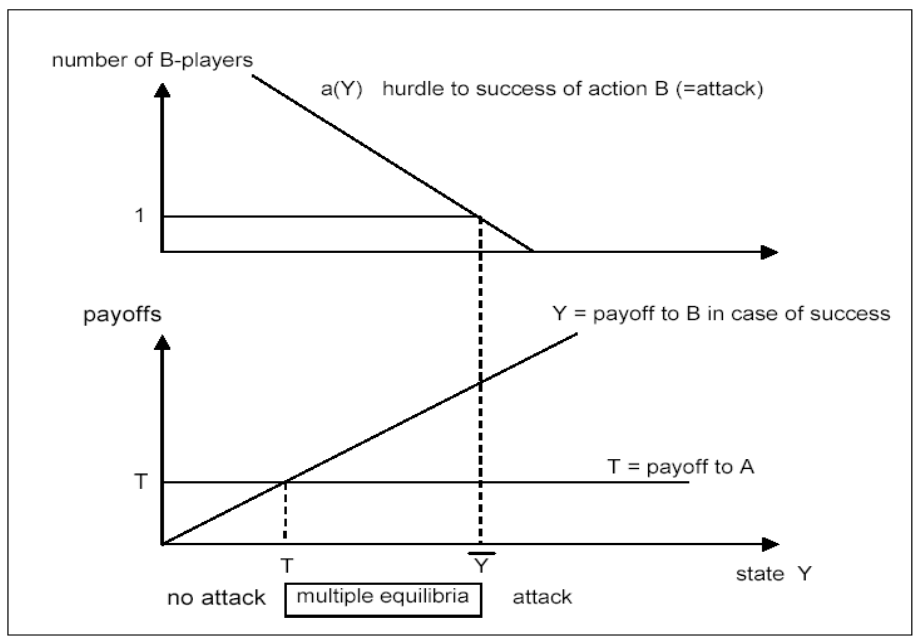

Figure 1 (Taken from HNO (2002)) - The speculative attack game. If at least $a(Y)$ traders attack (choose option B), the attacking traders receive a payoff $Y$. Otherwise they get 0 . If a trader does not attack (chooses option A), she gets $T$.

2.2.2. Private information

Morris and Shin (1998) assume that the fundamental state $Y$ has a uniform distribution on a sufficiently large support. Traders get random private signals $X_{i}$, which distribution is uniform conditional and independent on $[Y-\varepsilon, Y+\varepsilon]$, where $\varepsilon$ is sufficiently small. Each trader expects the other traders to receive more or less high signals compared to theirs with an equal probability. Common knowledge of the fundamental state disappears: it is replaced by an equilibrium condition, such that agents compare the expected payoff of a successful attack, weighted by the probability of success, to the transaction costs they have to pay with certainty. There exists a critical state of the economy below which an attack always occurs and above which an attack can never happen.

Private information, by avoiding total coordination on a pure self-fulfilling equilibrium, thus leads to the determination of a potentially better situation than public information, in terms of economic stabilisation. We call this situation the Private Information game (PI).

Heinemann and Illing (2002) show that more precise private information reduces the probability of a speculative attack. In order to minimise the probability of speculative attacks, the government should provide the agents with the best private information as possible but avoid common knowledge because of the danger of multiple equilibria.

2.2.3. Public and private informational signals

Between the two previous extreme cases (exclusive existence of public information or private information), Morris and Shin (1999) and Hellwig (2002) introduce private information and public information in the framework. The state $Y$ of the economy is assumed to be normally distributed: $Y \sim N\left(Z, \tau^{2}\right)$. Public information is the prior mean $Z$ and private information is given by $X_{i}=Y+\varepsilon_{i}, \varepsilon_{i} \sim N\left(0, \sigma^{2}\right)$.

Morris and Shin (1999) show that under certain conditions about the precision of public and private signals, equilibrium uniqueness can be guaranteed: uniqueness requires that private information be sufficiently precise compared to public information. In other words, the equilibrium is unique as soon as the noise is relatively small. We call this situation the simultaneous private and common signals game (PCS).

This framework changes the results in terms of policy implications compared to previous models. Morris and Shin (1999) find that the effects of private and public signals' precision are at best ambiguous. Extending previous results, Metz (2002) shows that with both public and private signals there exists an interaction between the two types of information: public and private information can have opposite effects on the prior probability of a crisis, depending on the prior mean of fundamentals. In the case of a bad fundamental state of the economy, the more precise public information and the less precise private information, the higher is the probability of a speculative attack. On the contrary, in a situation of good fundamentals a higher precision of the public signal and a lower precision of the private signal lead to a reduction in the probability of crisis.

Heinemann and Metz (2002) reconsider the problem of information disclosure when a central bank is threatened by a speculative attack on the fixed exchange rate by traders. Optimal risk and economic transparency are contingent to the prior probability of the expected mean of 
fundamentals: each time the prior probability of the mean of economic performance is under a certain threshold, the central bank should engage itself on the maximal risk and diffuse private information with a maximal precision; for good prior expectations, to the opposite, the optimal policy requires that the central bank avoids any risk and disseminates private information with the lowest possible precision. This can be explained as follows. If agents anticipate that the state is bad, they are strongly inclined to attack the currency. The fact to have no information incites agents to attack the exchange rate regime: without private information, the threshold of attack would be high, even if the fundamental state was much better than the expected state; with private information, agents can suppose that the state could be better. The central bank must then commit itself to disclose private information: agents become aware of the good states and will avoid the attack, if there is effectively a good fundamental state. If the state were bad, they would attack anyway (it is not possible to avoid an attack in a situation of bad fundamentals). Conversely, if prior expectations are good (high expectations of non attack), agents avoid the attack; giving private information cannot ameliorate the state of things. It is thus preferable for the central bank not to disclose any private information on the posterior state of fundamentals. In other words, if the market considers that the economy is in fundamentally good state, the central bank should commit itself to a low precision of private information so as to reduce the probability of attack, because an attack would occur anyway in a bad fundamental state.

Sbracia and Zaghini (2001) also study models with both public information and private information. According to them, "providing public information seems to be more convenient when fundamentals are "rather bad" than when fundamentals are "rather good"" (Sbracia and Zaghini, 2001, p. 19). The idea is the following: in a good state, with almost totally precise private information, there is no risk of attack; however, in bad states, with precise public information, multiple equilibria offer a chance to avoid attacks.

Morris and Shin (2002) underline that one of the drawbacks of this previously mentioned global game literature is that the study of the role of public information (owing to comparative statics) is rendered difficult by the complex effect arising from the interrelation between better fundamental information and changes in strategic uncertainty. They thus propose a more simple beauty contest model that avoids such a drawback by giving equilibrium uniqueness for any parameter of the model. They are able to study the role of the precision of private and public signals on welfare. They show that the noise in the public signal is given more weight than the noise in the private signal, which reflects the coordination motive of the agents and the disproportionate influence of the public signal in influencing the agents' actions. In terms of welfare effects, they get the following result. While welfare is unambiguously increasing in the precision of the private signals, increased precision of public information is beneficial only when the agents' private information is not very precise. Therefore, "when the private sector agents are already very well informed, the official sector would be well advised not to make public any more information, unless they could be confident that they can provide public information of very great precision" (Morris and Shin, 2002, p.19). The rationale for such a conclusion is that agents "overreact" to the public signal while suppressing the information content of the private signal. This underlines the importance of shared knowledge.

After evoking theoretical predictions of speculative attack models under different informational assumptions, we turn to the description of the experimental design of the game.

\section{Experimental design}

There exists only one experimental study, which tests the global game approach applied to speculative attack, that of HNO (2002). This study brought to evidence the fact that there is no big difference in the treatments of public and private information by agents. This paper tries to take this result into account and to go beyond it by testing the model under different informational assumptions.

\subsection{The protocol of Heinemann, Nagel and Ockenfels (2002)}

HNO (2002) are the first to present an experiment that imitates a speculative attack model (à la Obstfeld (1996) and Morris and Shin (1998)). We present their protocol from which we draw our inspiration.

They proceed to 25 sessions in total (in Germany and in Spain) with 345 participants (15 participants per session). Each session includes two stages with 8 independent rounds per stage. In each round, subjects where submitted to 10 independent situations, in which they had to decide between two alternative choices (A or B).

- Action A represents the risk-less choice, giving a positive and constant payoff $T$, which can be interpreted as the fact to avoid the costs linked to a speculative attack. It is a certain payoff. The two steps of each session were differentiated by the payoff linked to the choice A: in half of the sessions they started with $T=20$, then they took $T=50$ at the second stage; in the other sessions, they reversed the order.

- Action B is the risky action and can be interpreted as the attack, giving a payoff $Y$, if the number of subjects choosing B exceeds a certain threshold $a(Y)=15(80-Y) / W$, and 0 otherwise 
(the formula was given in the instructions, but also explained by an example and a table) ${ }^{2}$. Action $\mathrm{B}$ can thus give a positive payoff to the agent if a sufficient number of players chooses $B$ (this payoff is a function of the number of attacking agents but also of the fundamental value), and 0 otherwise.

More precisely, for each situation, the state $Y$ is randomly selected from a uniform distribution on the interval $[10,90]$. In common information sessions, players precisely knew the value of $Y$ and knew that everyone shared this information. In private information sessions, each agent received a private signal. Signals $X_{i}$ were randomly selected from a uniform distribution on the interval $[Y-10, Y+10]$ for each player separately; the received value was thus potentially different for each subject. Subjects knew that everyone of them only received private information and they shared the knowledge of the random process.

The rules of the game including the structure of uncertainty were common information among the subjects of each session. The experiment avoided any connotation that might be associated with "speculation" or "attack": subjects were simply asked to choose between two actions A and $\mathrm{B}$.

\subsection{The proposed protocol}

3.2.1. What is changed in our protocol?

To be able to compare the results of our experiment to the results of HNO (2002), we drew a protocol as close as possible to theirs. So we only did slight modifications, which do not have any impact on the unfolding of the game.

We firstly took the same number of players (15 players). Thresholds depend on the number of players, so we could keep the table giving the hurdle values. In addition, we kept the uniform distribution for convenience, although theoretical models use normally distributed signals. However, our values for $Y$ were integers.

Secondly, we added a phase where we asked participants questions about their understanding of the game, to avoid an education phase on the first rounds of the experiment. We asked simple questions which answers could be found in the instructions; they only proceeded when they answered correctly to the questions. To control for risk aversion of agents, we proposed a choice between the following alternative: a certain payoff of 2 euros and a lottery in which agents ${ }^{3}$ could earn 5 euros with probability $1 / 2$ and nothing with probability $1 / 2$.

\footnotetext{
${ }^{2}$ In 4 sessions, they applied $W=100$, in the others $W=60$.

In average, they were 10,5 out of 15 to choose the lottery.
}

Finally, we did only 6 sessions for each treatment. Consequently, we had to choose a fixed value for $W(W=60)$. But in each session, we kept the two stages with $T=20$ and $T=50$. The main change concerns the two treatments that are envisaged in the new experiment.

3.2.2. The representation of the new treatments in the protocol

Sessions were run in Regate (rooms 1 and 2) at GATE laboratory (Lyon 2 University, CNRS, France), on the $29^{\text {th }}$ and $30^{\text {th }}$ of September and $1^{\text {st }}$ of October 2003. We announced our experiment by e-mail to students of our data base (who already participated to experiments in the lab, but not to a coordination game) and to most of the students of EM Lyon and to new students of Ecole Centrale Lyon. We also put some posters at various places in Lyon 2 University and in ITECH. Most of the participants were business, economics or engineer undergraduates or graduates. During the three days, the procedure was kept the same throughout all sessions. All sessions were computerized, using a programme done with Regate (Zeiliger, 2000). Students were seated in a random order at PCs. Instructions were read aloud and questions were answered in private. Throughout the sessions students were not allowed to communicate and could not see others' screens.

We ran 6 sessions with two common signals (TCS) and 6 sessions with both private and common signals (PCS) (Table 1). Students could only participate once to the experiment.

\begin{tabular}{l|cc}
\hline Secure payoff $T$ & \multicolumn{2}{|c}{ Number of sessions with } \\
\cline { 2 - 3 } & 2 common signals & Both (simultaneous) private and \\
& 3 & public signals \\
$1^{\text {st }}$ stage $20 / 2^{\text {nd }}$ stage 50 & 3 & 3 \\
$1^{\text {st }}$ stage $50 / 2^{\text {nd }}$ stage 20 & \multicolumn{3}{c}{} \\
\hline
\end{tabular}

Table 1 -Sessions overview.

Analogously to HNO (2002), in each situation, the state $Y$ was selected randomly with a uniform distribution on the interval $[10,90]$ and was the same for all the agents. Our two treatments (simultaneous public and private information, and common multiple information) were constructed as follows:

- in simultaneous noisy public and private information sessions, each subject received a private signal $X_{i}$ randomly selected with a uniform distribution on the interval $[Y-10, Y+10]$ and all the subjects received on top of that the same signal $Z$ also randomly selected on $[Y$ $10, Y+10]$; the private value $X_{i}$ received by each agent was potentially different whereas the value $Z$ was identical for every agent; everyone knew this structure and shared the knowledge of the random process.

- in two public information sessions, all the agents received two common signals $Z_{1}$ and $Z_{2}$ and knew that all participants received these two signals with certainty; each signal was 
randomly selected with a uniform distribution on the interval $[Y-10, Y+10]$ and everyone knew this structure and shared the knowledge of the random process.

The presentation of the screen was very similar to HNO (2002). For each period, the secure payoff $T$ was always shown on the top of the screen. The two left columns displayed the private and public signals (called respectively "private hint number" and "common hint number") in the PCS condition or two public signals in the TCS condition (called "first common hint number" and "second common hint number"). In the right column subjects had to decide between A and B by clicking at either of two boxes. There was no presetting. Decisions could be changed until subjects clicked on the OK-button at the lower end of the screen. Once all players had completed their decisions in one round, they were informed for each situation about their own private signal, the common signal in PCS sessions or about the two common signals in TCS sessions, about $Y$ (true value), their choice, how many people had chosen B, whether the decision B was successful or not, their individual payoffs and the cumulative payoff over all 10 situations. After all players had left the information screen a new period started and information of previous periods could not be revised. Subjects were allowed to take notes and many of them did.

At the beginning of each session, participants had to write in a questionnaire (via computer) their personal data and fill in 7 understanding questions. At the end of each session, they had to respond to 4 (quite open) questions on a distributed paper (so that they were free to give any comment regarding the experiment). Once completed the questionnaire, each person was paid in private converting his or her total points into euros. Average payment per subject was 15 euros. Session length was around 1 hour and a half. The instructions are given in Appendix 8.1.

Now, we evaluate the impact of those different informational contexts on the mechanism of agents' coordination.

\section{Experimental evidence from the impact of the informational structure}

In this section, we examine the impact of the informational structure on the decision of agents, the probability of an attack, the predictability of an attack and the coordination of agents. But let's first give some general considerations about subjects' behaviour.

\subsection{General considerations about subjects' behaviour}

Before entering in the details of agents' behaviour, it is important to mention that agents followed threshold strategies and tended to consider more the public signal than the private one under the PCS condition.

4.1.1. The existence of threshold strategies

Subjects used threshold strategies whereas those strategies were not imposed on the subjects. As HNO (2002, p.9), we call a subject's behaviour "consistent with undominated thresholds" in some period, if her or his behaviour in that period was consistent with the existence of a threshold and did not exhibit any dominated actions. Accordingly, in TCS treatments, action $\mathrm{B}$ is dominated by $\mathrm{A}$ if $\operatorname{Max}\left\{Z_{1} ; Z_{2}\right\}<T-\varepsilon$ and $\mathrm{A}$ is dominated by B if Min $\left\{Z_{1} ; Z_{2}\right\}>\bar{Y}-$ $\varepsilon$; in PCS treatments, action $\mathrm{B}$ is dominated by $\mathrm{A}$ if $\operatorname{Max}\{X ; Z\}<T-\varepsilon$ and $\mathrm{A}$ is dominated by $\mathrm{B}$ if $\operatorname{Min}\{X ; Z\}>\bar{Y}-\varepsilon$.

With several signals, it is not at first glance clear which definition of threshold strategy to choose: the mean of the signals, the lowest signal, the highest signal? As shown in Table 9 (Appendix 8.2), subjects seemed to follow more threshold strategies as a mean of signals. A subject's behaviour is consistent with a threshold strategy as a mean of signals, if the highest mean signals, for which the subject chose A, is smaller than the lowest mean signals at which he or she chose B. This definition of threshold as a mean of signals is theoretically relevant as subjects obtained two signals of equivalent precision. Irrespective of the treatments, most of the subjects followed a threshold strategy (in average more than $70 \%$ for the first round, and more than $89 \%$ for the last round); however, for some participants, learning had an impact to understand the advantage of playing threshold strategies. Hence, playing threshold strategies does not seem to require as strong assumptions as theory predicts (i.e. common knowledge of the game structure).

4.1.2. The determinant signal for individual decision

Inside a treatment, what determines the decision of agents? Does private information have an impact on the decision? To answer such a question, we use logistic regressions done on individual decision. Table 11 (in Appendix 8.3.2) shows that:

- in PCS, the public signal plays a more important role in the decision taken by agents; - on the contrary, in TCS sessions, there is no clear use of one of the two public signals. Indeed, in 9 cases against 3, agents took more the public signal into account in the PCS treatment; whereas in 5 cases against 7 , agents took more the first public signal than the second one into account in the TCS treatment. This means that agents tend to consider the 
public signal as a focal point. Both the Binomial test and the Sign Test show that such a result is significant ( $p=0.019$ for the binomial test and $p=0.073$ for the sign test). Moreover, this is confirmed by the comments written by participants ${ }^{4}$.

As a consequence, the advantages and drawbacks of the potential for overreaction to public information have to be considered seriously by policy makers to determine how much they should disclose, in what form, and how often. As Morris and Shin (2002, p.4-5) put it: "Frequent and timely dissemination would aid the decision-making process by putting current information at the disposal of all economic agents, but this has to be set against the fact that provisional estimates are likely to be revised with the benefit of hindsight. By their nature, economic statistics are imperfect measurements of sometimes imprecise concepts, and no government agency or central bank can guarantee flawless information. This raises legitimate concerns about the publication of preliminary or incomplete data, since the benefit of early release may be more than outweighed by the disproportionate impact of any error".

In what follows, we try to catch the implications of this result and to find out whether it raises problems as feared by Morris and Shin (2002).

\subsection{Thresholds to successful attacks}

Not surprisingly, in all sessions, subjects tended to choose A for low signals or states and B for high signals or states. In consequence, the total number of players, who chose B, was rising with rising $Y$.

Tables 2 and 3 give an indication of the states where action B was successful in different sessions. Similarly to HNO (2002, p.13-14), for each treatment, we give an interval: the smaller number is the highest state up to which action B always failed; the larger number is the state from which on action B was always successful. The midpoint of the interval measures how thresholds depend on exogenous conditions. The width of the interval gives a measure of predictability of attacks. This will be used to ask how the information condition influences predictability within a session.

${ }^{4}$ However, logistic estimations testing for the role of individual risk aversion on individual decision did not exhibit any significant result.

\begin{tabular}{cc|cc}
\hline \multicolumn{2}{c|}{ Sessions with two common signals } & \multicolumn{2}{c}{ Thresholds to success } \\
\hline Session & Order & $\mathrm{T}=20$ & $\mathrm{~T}=50$ \\
30866249 & $20 / 50$ & $41-44$ & $56-61$ \\
34622802 & $20 / 50$ & $37-48$ & $52-61$ \\
49903521 & $20 / 50$ & $45-48$ & $54-55^{*}$ \\
27760776 & $50 / 20$ & $26-32$ & $30-57$ \\
35768884 & $50 / 20$ & $30-38$ & $37-56$ \\
50641587 & $50 / 20$ & $25-32$ & $26-56$ \\
\hline \multicolumn{2}{l}{ Table 2 - Thresholds to success in sessions with two common signals. A star indicates treatments where states }
\end{tabular}

with successful and failed attacks can be clearly divided.

\begin{tabular}{cc|cc}
\hline \multicolumn{2}{c|}{ Sessions with private and common } & \multicolumn{2}{c}{ Thresholds to success } \\
\hline signals & & & $\mathrm{T}=50$ \\
29520578 & Order & $\mathrm{T}=20$ & $52-55$ \\
37461307 & $20 / 50$ & $45-46^{*}$ & $57-59^{*}$ \\
28118404 & $20 / 50$ & $47-49^{*}$ & $47-59$ \\
37831221 & $20 / 50$ & $46-51$ & $54-57$ \\
53026879 & $50 / 20$ & $39-41^{*}$ & $33-55$ \\
53995310 & $50 / 20$ & $30-37$ & $54-58$ \\
\hline
\end{tabular}

Table 3 - Thresholds to success in sessions with private and common signals. A star indicates treatments where states with successful and failed attacks can be clearly divided.

In both sessions - and contrary to HNO (2002) -, most of the time we could not identify thresholds that clearly divided successful from failed attacks. There usually exists an overlap of states with successful and failed attacks. Random signals could deviate from the state by 10 units on the $Y$-scale. As a consequence, success or failure of an attack at any given state is unpredictable even if all individual strategies are known. At low states an attack may occur just because many subjects got much higher signals or reverse. In addition, this feature might also be due to the fact that receiving several signals (two instead of one in HNO (2002)) perturbed participants in defining a clear threshold above which they attack and under which they do not attack. For sessions with PCS, the lack of total common information should have worsened this effect because it hinders subjects to coordinate on the same strategy. Those features are illustrated by Figures 2 and 3 . 


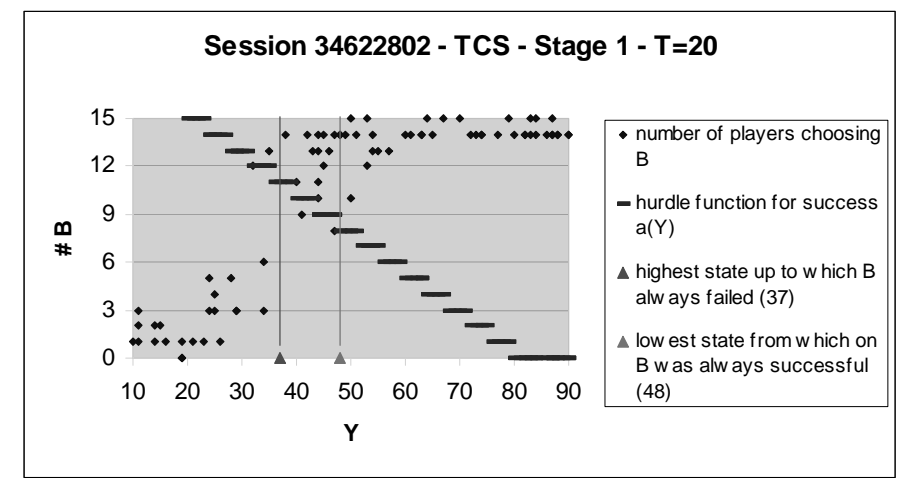

Figure 2 - Combined data from all eight periods of one stage of a session with two common signals. There are $80 \mathrm{Y}$-values selected in one stage. Dots indicate the associated number of subjects who chose B. The hurdle function is the minimal number of B-players needed for getting a reward while playing B. Dots below the hurdle function indicate states at which there was no successful attack. Dots on or above the hurdle indicate successful attacks. Two points indicate the highest state up to which action B always failed, and the lowest state from which on B was always successful. In this example, states with successful and failed attacks overlap, i.e. there are dots above and below the hurdle function within the interval defined by the two points already mentioned.

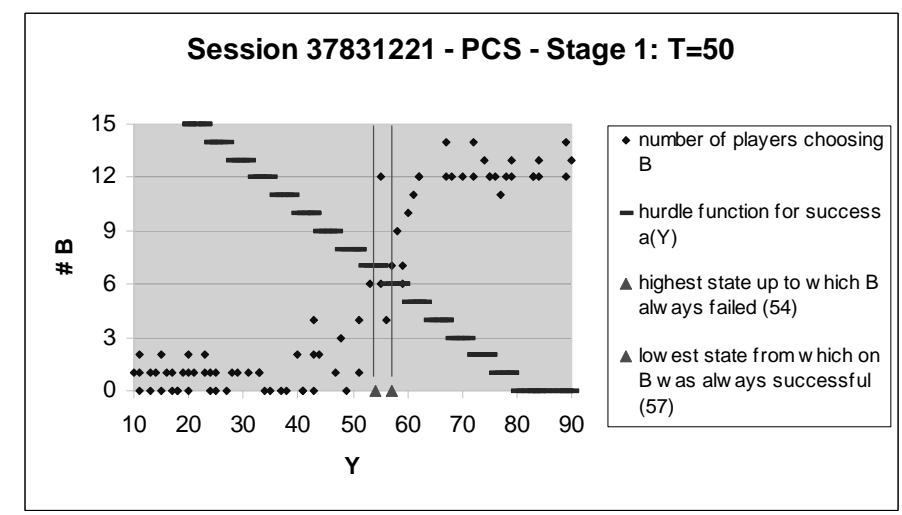

Figure 3 - Combined data from all eight periods of one stage of a session with both private and common signals. In this example, states with successful and failed attack also overlap.

However, judging from Tables 2 and 3, subjects seem to have a bit more coordinated on thresholds that clearly divided successful from failed attacks in sessions with PCS. Perhaps, the existence of a single common signal helped participants to decide on a threshold by serving as a focal point. This intuition is indeed confirmed by the analysis of probability and predictability of attacks and coordination.

\subsection{Probability and Predictability of Attacks}

To answer the question whether public information raises or lowers the probability on the one hand and the predictability of an attack on the other, we compare the characteristics of the states of successful and failed attacks in PCS and TCS treatments using aggregate behaviour analysis first and individual behaviour analysis afterwards.

4.3.1. Aggregate behaviour analysis

Table 4 contains a statistic of midpoints of the intervals of indeterminacy as a measure of thresholds to success. In addition, it gives the average width of the intervals of indeterminacy (i.e. between the highest state, up to which on action B always failed and the lowest state, from which on action B was always successful) that will be used as a measure of predictability of an attack.

\begin{tabular}{l|cc}
\hline \multicolumn{1}{c|}{ Treatment } & $T=20$ & $T=50$ \\
\hline Sessions with TCS & 36.37 & 54.88 \\
Mean thresholds to success & 7.0 & 6.7 \\
Standard deviation & 6.33 & 15.17 \\
Average width of the interval of indeterminacy & $(6)$ & $(6)$ \\
(Number of sessions) & 41.33 & 56.36 \\
\hline Sessions with PCS & 6.2 & 4.5 \\
Mean thresholds to success & 3.5 & 7.67 \\
Standard deviation & $(6)$ & $(6)$ \\
Average width of the interval of indeterminacy & Number of sessions) &
\end{tabular}

Table 4 - Observed mean thresholds to success and average width of the interval between the highest state, up to which action B always failed and the lowest state, from which on action B was always successful.

The mean threshold to success is always higher in simultaneous private and public signals than in otherwise equal treatments with two common signals. The standard deviation is however larger in the TCS than in the PCS condition. Those results can be explained by the fact that, in the PCS condition, the existence of a single public signal served as a focal point, whereas in the TCS treatment there could be confusion in focal points (the first common hint, the second one or the mean of these two values). 
Probability of successful attack

The higher the threshold to success, the smaller is ex ante probability for states, at which subjects succeed to play B. This is interpreted as a lower prior probability for speculative attacks that enforce devaluation.

For a systematic analysis of the influence of information and other control variables on mean thresholds we use linear regressions. We determine whether threshold states $Y^{*}$ from which on an attack is likely to occur depends on various exogenous conditions or not. Regression 4 shows that $T$ explains $67 \%$ of all data variation; Regression 5 shows that information and order of treatment increase this to $92 \%$ (see Table 13, Appendix 8.3.3). However, the number of risk adverse subjects has no significant impact on the determination of the threshold level (Regression 8)

From this analysis, we can deduce that information has a significant impact on the level of the threshold. However, order has a stronger influence. Like in HNO (2002), surprisingly, thresholds tend to be higher in sessions where we started with a low payoff for the secure action $(T=20)$ than in sessions where we started with a high payoff $(T=50)$. Therefore something irrelevant (as the order in which participants are asked to play) can have a greater impact on the probability of attack than some other obviously relevant element (information). This can explain for example that there has sometimes been an attack at a moment where news was irrelevant to it. In some sense, attacks are not really predictable (or have at least a probability of occurrence which can vary according to irrelevant news).

Predictability of attacks

We now consider whether there is any difference in predictability of thresholds related to the information condition.

Firstly, comparing the standard deviations of average thresholds in previous Table 4 above, it seems that the information condition has an impact on the dispersion of observed thresholds among otherwise equal treatments. This impression is supported by separate regressions of thresholds for both information conditions. Indeed, regressions 6 and 7 (see Table 13, Appendix 8.3.3) show that there is a small difference between TCS and PCS conditions. Moreover, the standard variation of residuals is 6.21 in sessions with TCS and 7.52 in sessions with PCS. Thus, we clearly see that this interval is larger with PCS than with TCS.

Secondly, the differences in the predictability within a session can also be measured by the width of the interval between the highest state up to which action B always failed and the lowest state from which on action B was always successful (see Table 4 above). These intervals tend to be wider for TCS. We check whether the difference between the lowest state, from which on all attacks succeeded, and the highest state, up to which all attacks failed, has any relation to exogenous conditions. On average over all sessions with TCS the intervals of states for which there is no clear indication of whether attacks fail or succeed has width 12. In treatments with both private and public signals, its width is 7.1 on average. This result is quite different from HNO (2002, p.17) for whom "private information increases the range of states for which we cannot predict whether an attack is successful or not". Regressions 11 and 12 (see Table 14, Appendix 8.3.3) show that the difference in information conditions is hardly significant (around 10\%-level). This would mean that with TCS the range of states for which a state falls into the region of indeterminacy increases by 4.9 compared to PCS. This difference in results (compared to HNO) might be explained by the fact that the single common signal serves as a coordination point, similarly to CI treatments in HNO (2002) (see section 5. below).

4.3.2. Individual behaviour analysis

Previous aggregate results are confirmed by the analysis of individual behaviour. We use a logistic regression done on individual decision ${ }^{5}$. We estimate for each session the proportion of agents who are choosing B (which is an increasing function in signals) by a logistic estimation ${ }^{6}$; thus the mean of this function gives us an estimation of the probability of crisis and its variance represents a measure of predictability of crisis.

We estimate the distribution of thresholds for each round of each session using a logistic estimation; results may be interpreted in two ways:

- as estimated probabilities for subjects choosing B conditional on hints $Z_{1}$ and $Z_{2}$ or hints $X$ and $Z$, respectively,

- as estimated distribution of individual thresholds.

Table 12 in Appendix 8.3.2 gives statistical information on session specific results. Table 5 gives a summary statistic of estimated means and estimated standard deviations of individual thresholds for distinguished treatments.
${ }^{5}$ Because of problems of complete data separation, we could not directly use the (aggregate) probability of

success in our logistic estimation.
${ }^{6}$ The logistic distribution is more appropriate than the normal distribution, because we observe "fat tails" due to irrational behaviour of a few subjects who do not play threshold strategies. 


\begin{tabular}{l|cc}
\hline Treatment & $T=20$ & $T=50$ \\
\hline Sessions with TCS & & \\
Average estimated mean of individual thresholds & 34.07 & 54.49 \\
Average estimated standard deviation & 9.95 & 6.82 \\
Number of sessions & $(6)$ & $(6)$ \\
\hline Sessions with PCS & 39.46 & 57.40 \\
Average estimated mean of individual thresholds & 11.04 & 9.86 \\
Average estimated standard deviation & $(6)$ & $(6)$ \\
\hline Number of sessions & \multicolumn{2}{l}{} \\
\hline \multicolumn{2}{l}{ Table 5 - Average estimated means and standard deviations of individual thresholds to action B. }
\end{tabular}

\begin{tabular}{ll} 
Number of sessions & $(6)$ \\
\hline Table 5 - Average estimated means and standard deviations of individual thresholds to action $B$.
\end{tabular}

Probability of successful attack

It clearly appears that the estimated probability of successful attack is always smaller in the PCS treatment. To check such a conclusion, we run a linear regression using the controlled variables to explain the estimated mean threshold of each session (see Regression 16, in Table 15, Appendix 8.3.3). This reinforces previous results according to which the informational structure has a significant impact on the probability of attack even if this impact is smaller than that of "irrelevant" variables (such as the order), implying that speculators can overreact to irrelevant news (and thus coordinate on "sunspots")

$$
\text { Predictability of attacks }
$$

Table 5 tends to show the exact opposite of what was found earlier: the average estimated standard deviation is always larger in the PCS case. However, the linear regression 17 (see Table 15, Appendix 8.3.3) using controlled variables to explain standard deviations of individual thresholds shows that such a result is not significant at all.

As a consequence, in terms of economic policy, we can draw the following conclusion from our previous results. The central bank can reduce the probability of an attack and has more control on the beliefs of traders if it discloses one clear (and precise) single signal, even if agents get private information from other sources. By giving several public signals, it lowers its focal potential. The loss of predictability linked to uncontrolled private information is largely outweighed by the increase of predictability related to the existence of a focal point. What is the impact of the existence of such a focal point on coordination failures?

\subsection{Coordination Failures}

We now turn to the analysis of coordination in function of the informational structure given to participants. The objective of this section is to study the impact of public information vs. private information in PCS sessions on coordination (while testing at the same time whether a first public signal has more impact than a second one in TCS sessions). We first give an overview on coordination before measuring it as well as determining efficiency and welfare losses.

4.4.1. An overlook on coordination

We establish some very general results about the impact of the treatments on coordination. To start with, we establish the impact of the treatment on extreme situations: perfect coordination $v s$. total coordination failure. We define perfect coordination as the situation in which all agents chose the same action and total coordination failure as the situation in which only half of the subjects ( 7 or 8 ) play the same action. Table 6 gives the respective percentages of occurrence of these situations.

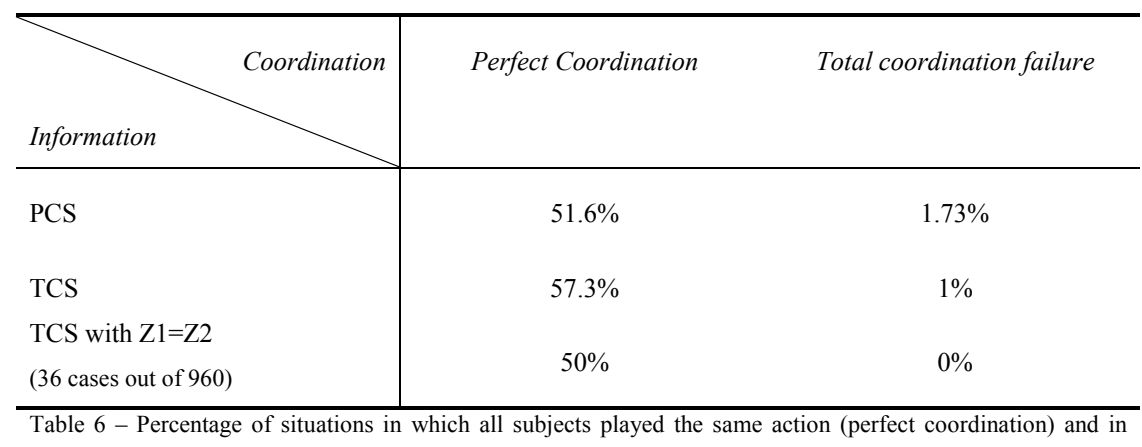

which 8 or 7 played the same action (total coordination failure) in function of the informational structure they

It appears that perfect coordination is better achieved in TCS than in PCS sessions and total coordination failure happens more in PCS than in TCS sessions. This very approximate estimation of coordination is confirmed by all the intermediate values for coordination.

We also address the question whether, when $Z_{1}=Z_{2}$ in TCS, the number of attacking agents increases or not (so that it increases coordination). Such a situation takes place in 36 cases out of 960 and seems to have a negative impact on coordination: in such a case, subjects receive a less precise indication on the true state (very different hints give them a better idea of the fundamental state), which may hinder coordination or make it more difficult. This result is very much in line with the theory: subjects seem to make bayesien update. On the other hand, there is confusion about on which common signal to coordinate. Empirically, we could have expected that the fact to receive two identical signals could have reinforced agents in the idea that this value, as repeated, was the true value; indeed the estimation of the fundamental could have been psychologically counterintuitive. 
However, the Kolmogorov-Smirnov two-sample two-tailed test (on all the cumulated intermediate values for coordination - between perfect coordination and total coordination failures) shows that we can reject such a hypothesis with a very high degree of significance: there is no significant difference linked to the informational structure on coordination achievement. Such a result is confirmed by a more systematic measure of coordination.

4.3.2. A measure of coordination

To measure coordination (while distinguishing between its effect and the level of threshold), we calculate the number of regrettable decisions. According to HNO (2002, p.18), when individual behaviour is not perfectly coordinated, subjects experience mistakes in the information phase and learn to adjust their thresholds toward each other. There are two possible situations in which a subject could regret her decision:

- she chose B and received 0 (a failed attack),

- she chose A, when B would have given a higher reward (a missed opportunity to attack).

These situations should not occur when a subject can predict whether an attack will be successful or not. The total number of cases where subjects could regret their decisions gives us a measure for their ability to predict whether an attack will be successful or not.

Figure 4 shows the average number of decisions where a subject could have improved her payoff by deciding differently. If the number of regrettable decision is not particularly high (except in the first three periods), there are more regrettable decisions with PCS than with TCS. However this difference is not striking and the figure does not show a clear trend over time?

The analysis of coordination measured with the number of regrettable decisions shows that there is no overreaction to the focal public signal in the PCS treatment. Indeed, the presence of private information compensates the potential disproportionate outweigh associated with public information (that can be mistaken). Thus private information has a stabilising effect, as suggested by global game models: while sunspots can occur under TCS condition because of self-fulfilling beliefs, those are avoided by private information in the PCS case.

${ }^{7}$ Note that the change of treatment in period 9 strongly increased the number of regrets.

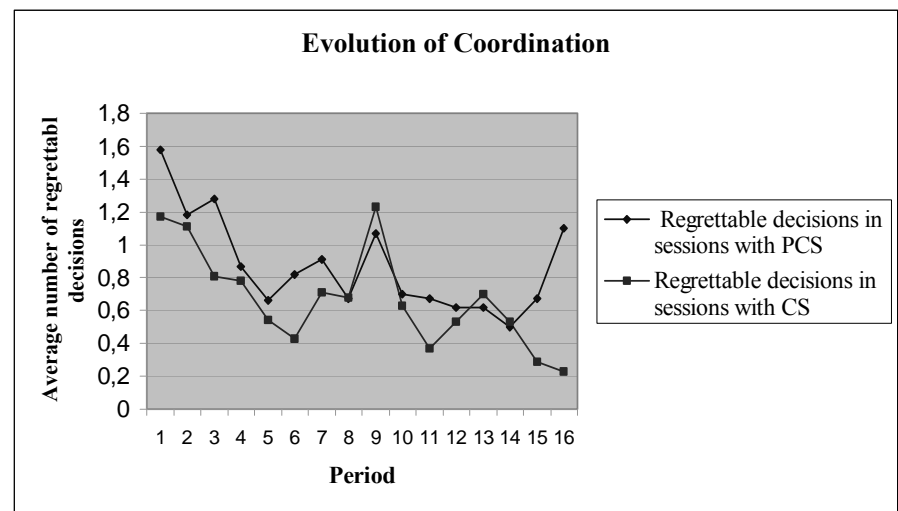

Figure 4 - Average number of situations in which a subject could have achieved a higher payoff by a different decision.

\subsection{Efficiency and welfare losses}

We test welfare effects of coordination failures (how a better coordination on a better equilibrium could have increased welfare - for speculators but not for the central bank as its utility function is not modelled here). To this aim, we compare the maximum value in ECU that subjects could have obtained to what they got in reality.

As expected, welfare losses were the highest for values of $Y$ close to $T$ and the lowest for extreme values of $Y$. Indeed, coordination is mainly problematic for critical, intermediate values of $Y$. The zone of $Y$ for which welfare losses are high is larger in PCS than TCS treatments. Moreover, these welfare losses were higher in PCS than TCS, as the analysis in terms of coordination could predict it.

The rationale for such a result can be found owing to previous conclusions about the focal role of the public signal in the PCS treatment. Focusing on the public signal - and ignoring the private one -, subjects receive less precise signals in the case of PCS sessions than in the case of TCS sessions where they consider both. Therefore, they had a better hint about the true value of $\mathrm{Y}$ in the TCS case. Welfare losses for speculators were thus accentuated in PCS treatments. The public signal serves as a focal point for the beliefs of the group as a whole, but here it also conveys less precise information on the underlying fundamentals than the two public signals in the TCS sessions. The precision of signals thus plays an important role. Individual speculators' welfare is increased by an increased precision in the disclosed signals. 
Figures 5, 6, 7 and 8 illustrate this feature by representing effective welfare losses in percentage of the maximum gains in function of the true fundamental state for each session. The value of $Y$ for which welfare losses are the highest are really stable across sessions and relatively higher when $T=20$.

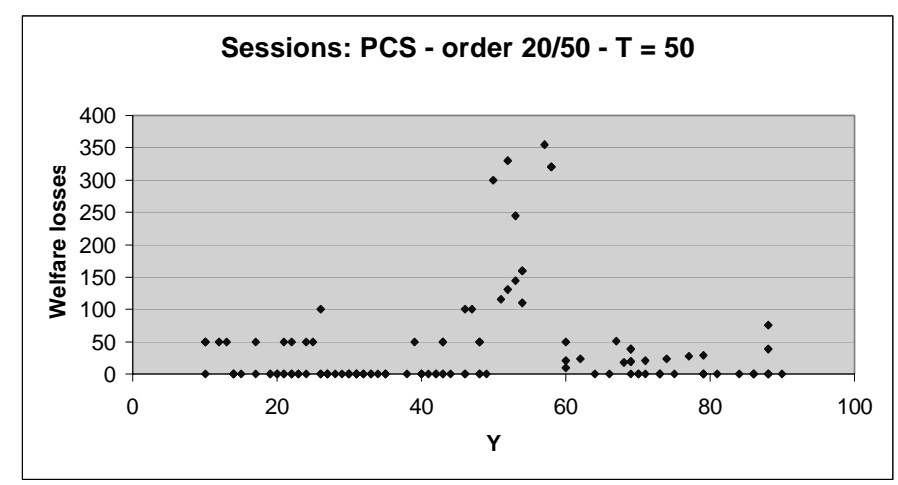

Figure 5 - Average percentage of welfare losses in ECU in function of $Y$ for the last 4 rounds in PCS sessions which order is $T=20$ and then $T=50$ and for which $T=50$.

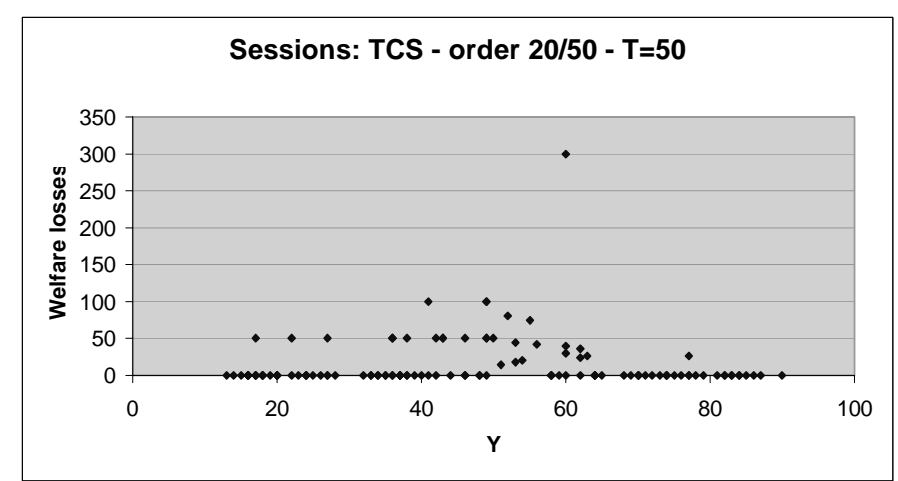

Figure 6 - Average percentage of welfare losses in ECU in function of $Y$ for the last 4 rounds in TCS sessions which order is $T=20$ and then $T=50$ and for which $T=50$.

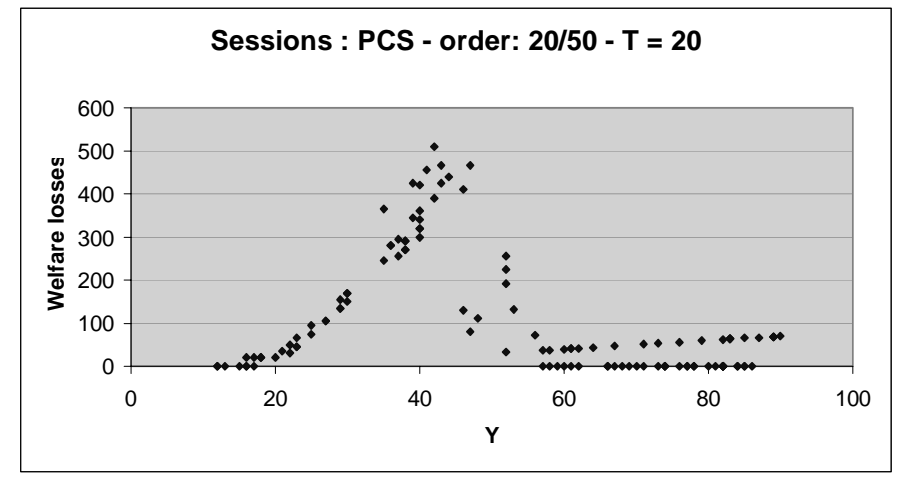

Figure 7 - Average percentage of welfare losses in ECU in function of $Y$ for the last 4 rounds in PCS sessions which order is $T=20$ and then $T=50$ and for which $T=20$.

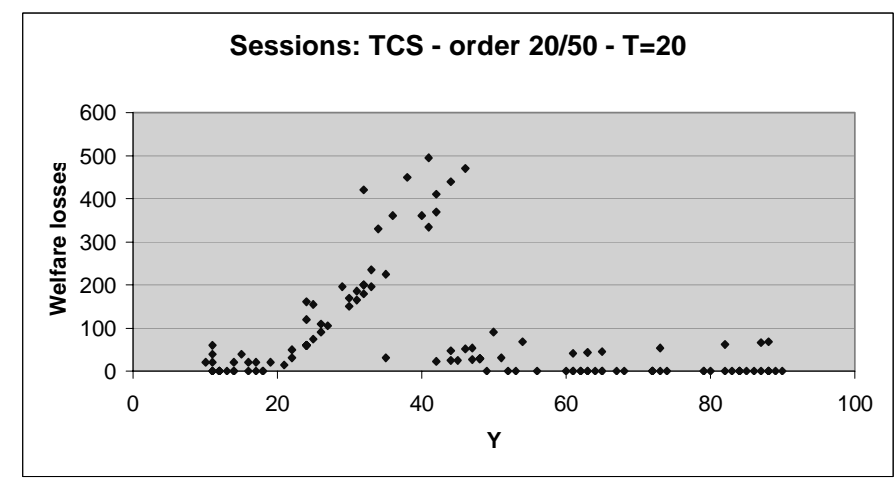

Figure 8 - Average percentage of welfare losses in ECU in function of $Y$ for the last 4 rounds in TCS sessions which order is $T=20$ and then $T=50$ and for which $T=20$.

\section{Comparison of the results with previous experiments}

In this section, we propose to compare our experimental results to the previous experiment done by HNO (2002). To make such a comparison, we take in HNO (2002) only the sessions with $W=60$. This comparison aims at better understanding the coordinating effect of public information and its potential drawbacks linked to self-fulfilling beliefs. Nevertheless, the following results have to be taken into account with caution because even if this experiment was a close as possible to the protocol of HNO, we already mentioned some differences. More especially, coordination games are very sensible to different subjects' pools. 
We compare first the probability of attack, then the predictability of attack and finally the coordination failures in each informational context. Table 7 recapitulates the different elements of comparison between both experiments, on which we base our analysis.

\begin{tabular}{|c|c|c|c|c|c|c|}
\hline \multirow{2}{*}{\multicolumn{2}{|c|}{$\begin{array}{c}\text { Informational structure/ } \\
\text { Average Results }\end{array}$}} & \multicolumn{2}{|c|}{$\begin{array}{l}\text { Probability of Attack } \\
\text { (Thresholds' value) }\end{array}$} & \multicolumn{2}{|c|}{$\begin{array}{c}\text { Predictability of } \\
\text { Attack } \\
\text { (Thresholds' } \\
\text { dispersion) }\end{array}$} & \multirow[t]{2}{*}{$\begin{array}{c}\text { Size of } \\
\text { Coordination } \\
\text { Failures }\end{array}$} \\
\hline & & $T=20$ & $T=50$ & $T=20$ & $T=50$ & \\
\hline CI & \multirow[t]{2}{*}{ Treated by HNO (2002) } & 40.47 & 52.78 & 4.5 & 2.2 & 0.59 \\
\hline PI & & 44.16 & 54.74 & 4.0 & 2.8 & 1.19 \\
\hline TCS & \multirow[t]{2}{*}{ New treatments } & 36.37 & 54.88 & 7.0 & 6.7 & 0.67 \\
\hline PCS & & 41.33 & 56.36 & 6.2 & 4.5 & 0.87 \\
\hline
\end{tabular}

\subsection{Probability of attack}

There is no clear evidence of the treatment that lowers (respectively highers) the probability of attack. Indeed, results are different depending on the value of $T$.

However, our analysis confirms the results of HNO (2002): comparing treatments with $T=20$ with otherwise equal treatments with $T=50$, the threshold clearly rises in $T$; this means that opportunity costs of an attack reduce the probability of devaluation. In other words, capital controls reduce the probability of successful attacks.

\subsection{Predictability of attack}

Decentralised information (i.e. several sources of information or several signals) tends to reduce the predictability of attacks. Indeed for both values of $T$, in the new proposed treatments, thresholds' dispersion is always much higher (around 6 in average) than in treatments treated by HNO (2002) (around 3 in average). As already mentioned, this result is even stronger for TCS treatments, probably because of the same public nature of both signals.

\subsection{Coordination failures}

Table 7 shows that having only one public (and unmistaken) signal favours coordination. The existence of several focal points (several public signals) perturbed coordination. The presence of public information (in sessions with both types of signals compared to PI conditions) clearly shows the coordinating effect of the public nature of signals. Coordination failures are the most numerous in private information sessions. The rationale for such a result is rather intuitive.
However, the comparison is plagued by the fact that the number of regrettable decisions comprehends on top of the measure of coordination a measure of signals' precision. Yet, the precision of the common information treatment is perfect whereas the other informational structures are of imperfect precision.

\section{Conclusion}

The following table sums up the main results of this paper in comparing empirical evidence to theoretical predictions in terms of informational disclosure policy.

The main economic policy conclusion we can draw from our experiment is the following. The central bank can reduce the prior probability of a crisis and higher its focal potential if it discloses a single signal, in a context where agents additionally get private information from diverse sources

An interesting extension of our research would be to experimentally analyse more closely the evidence of informational precision on subjects' decisions.

\begin{tabular}{|c|c|c|}
\hline $\begin{array}{l}\text { Basic } \\
\text { framework }\end{array}$ & Theoretical predictions & Empirical evidence \\
\hline \multicolumn{3}{|c|}{ Results of HNO (2002) } \\
\hline $\begin{array}{lr}\text { One } & \text { public } \\
\text { signal } & \\
(\text { Obstfeld, } & 1996)\end{array}$ & $\begin{array}{l}\text { Destabilisation: } \\
\text { The public signal is a focal point but can } \\
\text { provoke an overreaction of agents. }\end{array}$ & $\begin{array}{l}\text { - Probability: higher than one private signal } \\
\text { treatment. } \\
\text { - Predictability: high. } \\
\text { - Coordination: always better achieved. }\end{array}$ \\
\hline $\begin{array}{lr}\text { One } & \text { private } \\
\text { signal } & \\
\text { (Morris } & \text { and } \\
\text { Shin, 1998) }\end{array}$ & $\begin{array}{l}\text { Stabilisation if private information precise } \\
\text { enough: } \\
\text { The presence of private information leads to } \\
\text { higher order beliefs, which prevent from } \\
\text { overreaction of agents to any signal. }\end{array}$ & $\begin{array}{l}\text { - Probability: relatively low. } \\
\text { - Predictability: high. } \\
\text { - Coordination: the least efficient. }\end{array}$ \\
\hline \multicolumn{3}{|c|}{ Our experimental results } \\
\hline $\begin{array}{l}\text { Two common } \\
\text { signals }\end{array}$ & $\begin{array}{l}\text { Same as having a noisy public signal } \\
\text { Destabilisation: } \\
\text { There is a potential damage linked to the } \\
\text { noise in public information. }\end{array}$ & $\begin{array}{l}\text { - Probability: no significant difference } \\
\text { compared to other situations, but higher than } \\
\text { PCS. } \\
\text { - Predictability: low (the worst). } \\
\text { - Coordination: good but less efficient than in } \\
\text { CI sessions }\end{array}$ \\
\hline $\begin{array}{l}\text { One public } \\
\text { signal and one } \\
\text { private signal } \\
\text { (Morris and } \\
\text { Shin, 2002) }\end{array}$ & $\begin{array}{l}\text { Stabilisation if private information precise } \\
\text { enough compared to public information: } \\
\text { The public signal serves as a focal point } \\
\text { while at the same time the presence of } \\
\text { private information avoids agents, } \\
\text { overreaction. }\end{array}$ & $\begin{array}{l}\text { - Probability: no significant difference } \\
\text { compared to all other situations, but lower } \\
\text { than TCS. } \\
\text { - Predictability: low, but better than TCS. } \\
\text { - Coordination: coordination is better } \\
\text { achieved on the public signal. }\end{array}$ \\
\hline
\end{tabular}




\section{References}

BASEL COMMITTEE ON BANKING SUPERVISION [1999], Recommendations for Public Disclosure of Trading and Derivatives Activities of Banks and Securities Firms, Bank for International Settlements, Basel.

CABRALES A., NAGEL R., ARMENTER R. [2002], "Equilibrium Selection through Incomplete Information in Coordination Games: An Experimental Study". http://www.econ.upf.es/ cabrales/research/WP.html

HEINEMANN F. [2002], "Exchange Rate Attack as a Coordination Game: Theory and Experimental Evidence", Oxford Review of Economic Policy, vol. 18, $\mathrm{n}^{\circ} 4$ http://www.sfm.vwl.uni-muenchen.de/heinemann/download/oxrep-2.pdf

HEINEMANN F., ILLING G. [2002], "Speculative Attacks: Unique Equilibrium and Transparency", Journal of International Economics, 58, pp. 429-450.

http://www.sfm.vwl.uni-muenchen.de/heinemann/download/attacks.pdf

HEINEMANN F., METZ C. [2002], "Optimal Risk Taking and Information Policy to Avoid Currency and Liquidity Crises", University of Kassel Discussion Paper, 31/02.

http://www.sfm.vwl.uni-muenchen.de/heinemann/download/heime.pdf

HEINEMANN F., NAGEL R., OCKENFELS P. [2002], "Speculative Attacks and Financial Architecture: Experimental Analysis of Coordination Games with Public and Private Information".

http://www.sfm.vwl.uni-muenchen.de/heinemann/download/HNO4.pdf

HELLWIG C. [2002], "Public Information, Private Information and the Multiplicity of Equilibria in Coordination Games", Journal of Economic Theory, vol. 107, pp. 191-222.

http://econ.lse.ac.uk/phdc/papers/hellwig_imp.pdf

INTERNATIONAL MONETARY FUND [1998], Report of the Managing Director to the Interim Committee on Strengthening the Architecture of the International Monetary System. http://www.imf.org/external/np/omd/100198.htm

METZ C. [2002], "Private and Public Information in Self-Fulfilling Currency Crises", Journal of Economics, vol. 76, $\mathrm{n}^{\circ} 1$, pp. 65-85.

MORRIS S., SHIN H.S. [1998], "Unique Equilibrium in a Model of Self-fulfilling Currency Attacks", American Economic Review, vol. 88, n 3, June, pp. 587-597.

MORRIS S., SHIN H.S. [2004], "Coordination Risk and the Price of Debt", European Economic Review, vol. 48, pp. 133-153. http://www.econ.yale.edu/ sm326/research.html

MORRIS S., SHIN H.S. [2002], "Social Value of Public Information", American Economic Review, vol. 92, n5, December, pp. 1522-1534.

OBSTFELD M. [1996], "Models of Currency with Self-fulfilling Features", European Economic Review, vol. 40, pp. 1037-1047.

SBRACIA M., ZAGHINI A. [2001], "Expectation and Information in Second Generation Currency Crises Models", Economic Modelling, 18, pp. 203-222.

ZEILIGER R. [2000], A presentation of Regate, Internet based Software for Experimental Economics. http://www.gate.cnrs.fr/ zeiliger/regate/RegateIntro.ppt, GATE.

\section{Appendices}

\subsection{Instructions according to the different informational treatments}

Instructions to participants varied according to the different treatments. We present the instructions for a session with simultaneous public and private information (with $T=20$ in full length, for the other sessions instructions were adapted accordingly). The instructions for two common signals treatments were adapted and are available upon request ${ }^{8}$.

General information

Thank you for your participation to an economic experiment, in which you have the chance to earn money. We ask you not to communicate from now on. If you have a question, then raise your hand, and one of the instructors will come to you.

You are one of 15 persons, who interact with another. The rules are the same for all participants. The experiment consists of 2 stages with 8 independent rounds in each stage. In each round you will receive 10 independent situations, in each of which you have to make a decision (A or B).

Rules of the first stage (the two stages differ only by the payoff for decision A):

\section{Decision situation:}

For each situation a number called $Y$ is drawn randomly from the interval 10 to 90 . This number is the same for all participants. All numbers in the interval $[10,90]$ have the same probability to be drawn. When you make your decision, you will not know the drawn number

However, you will be receiving two types of information on $Y$

- Each participant will receive a private hint number $X$ for the unknown number $Y$. This private hint number $X$ is randomly selected from the interval $[Y-10, Y+10]$. All numbers in this interval have the same probability to be drawn. Private hint numbers of different participants are drawn independently from the same interval. Each private hint number is thus potentially different for each participant.

- All participants will receive, on top of that private hint number $X$, a common hint number $Z$ - All participants will receive, on top of that private hint number $X$, a common hint number $Z$
for the unknown number $Y$. This common hint number is randomly selected from the interval $[Y-10, Y+10]$. This common hint number $Z$ is thus the same for every participant.

On basis of these hint numbers $X$ and $Z$ you can decide in each situation between two different decisions: A or B.

If you decide for A, then an amount of $20 \mathrm{ECU}$ (Experimental Currency Unit) is credited to your account. This amount is the same for all rounds of the first stage and for all participants (in the second stage the amount is raised to $50 \mathrm{ECU}$ ).

If you decide for $\mathrm{B}$, then your payoff depends on how many participants select the same decision $\mathrm{B}$ and also depends on how large is the unknown number $Y$. Decision B is the more successful, the more participants decide for B and the larger the number $Y$ is. If the number of participants who decide for B is at least $20-Y / 4$, then each participant, who decided for $\mathrm{B}$, receives the amount of $Y$ ECU. A more exact explanation of this formula is given help of an example and the table at the end of the instructions. If fewer participants decided for $\mathrm{B}$, then those choosing $\mathrm{B}$ receive zero $\mathrm{ECU}$.

Once all participants made their 10 decisions for the 10 games, a round is terminated. (Remember there are 8 rounds in each of the two stages).

${ }^{8}$ Here is a translation (from French to English) of the instructions given to the participants. 
Each participant will be informed after each round for each of the 10 games on (1) the number $Y$,

(2) how many participants decided for A or B,

(3) the own payoff and also the total sum of the own payoffs over all 10 games.

\section{Example:}

The number of participants is 15 . The payoff for $\mathrm{A}$ is always 20 . The unknown number $\mathrm{Y}$, which was drawn, is 48

The private hint numbers $X$ drawn for each of the fifteen participants are: $38,45,42$, 56, etc.

The common hint number $Z$ drawn for the fifteen participants is: 52 .

Every participant knows with the common hint number $Z=52$ that $Y$ is between 42 and 62 . So:

- the participant with his private hint number $X=38$ knows, on top of that, that $Y$ is between 28 and 48; from which he can deduce that $Y$ is between 42 and 48;

- the participant with his private hint number $X=45$ knows, on top of that, that $Y$ is between 35 and 55; from which he can deduce that $Y$ is between 42 and 55.

etc.

Six participants decide for A, nine participants decide for B

The participants, who chose A, receive $20 \mathrm{ECU}$.

In order to receive a positive payoff for B, at least $20-48 / 4=8$ (remember the formula (20$Y / 4)$ ) participants have to decide for B (that is 8 or more). Since 9 participants selected B, each of them receives $Y=48$

For the calculation of the minimum number of the participants needed such that payoff for B is positive see attached table:

Since $Y=48$, the number of participants must be 8 in order to get a positive payoff for decision B.

Note: You don't know the true value of $Y$, but you receive two hint numbers, which are approximations of $Y$. Therefore you cannot exactly determine how many players must select $\mathrm{B}$, in order to get a positive payoff.

\section{For the calculation of the minimum number of participant's who have to choose $B$ in} order to get a positive payoff for $B$ :

Participants, who choose B, receive a positive payoff, only if at least $20-Y / 4$ participants choose B.

In the right hand column you find the minimal number of participants and in the left column the according intervals for $Y$

\begin{tabular}{l|l}
\hline $\begin{array}{l}\text { If the unknown number } Y \text { is in the interval, } \\
\text { (Note: } Y \text { is between } 10 \text { and } 90 \text { ) }\end{array}$ & $\begin{array}{l}\text { Then at least ... of the } 15 \text { participants } \\
\text { (including yourself) have to select } B \text {, in order } \\
\text { to get a positive payoff }\end{array}$ \\
\hline 10 to 23 & 15 \\
24 t 27 & 14 \\
28 to 31 & 13 \\
32 to 35 & 12 \\
36 to 39 & 11 \\
40 to 43 & 10 \\
44 t 47 & 9 \\
48 to 51 & 8 \\
52 to 55 & 7 \\
56 to 59 & 6 \\
60 to 63 & 5 \\
64 to 67 & 4 \\
68 to 71 & 3 \\
72 to 75 & 2 \\
76 to 90 & 1 \\
\hline
\end{tabular}

\section{Instructions for PC:}

Each round is divided into a decision phase and into an information phase. During the decision phase the screen shows the current round in the heading line. The second line informs you about the sure payoff for decision A. The following table shows your private hind number $X$ and the common hint number $Z$ of everybody for each game in the left column. In the right column you must click which decision you want to select. Once you red button, you can still modify your decisions. When exceeding the time limit you are reminded to make your decisions.

When all participants have pressed the OK-button, the decision phase of a round is terminated and the information phase begins. The display in the information phase indicates line by line for each situation of this round the true value $Y$, the number of players, who decided for $\mathrm{B}$, your own decision, and the change of your account balance. After the time limit the next round starts. In addition you can leave the information phase beforehand through the OK button. After leaving the information screen you have no more possibility to inform yourself about passed decisions.

\section{Questionnaire:}

At the end of the experiment (after the second stage) we ask you to fill out a questionnaire. The personal data asked for are treated strictly confidential and used for research purposes only.

\section{Payoffs:}

Also at the end of the experiment the ECUs you have obtained are converted into Euros and paid in cash. $1 \mathrm{ECU}$ corresponds to 0.166 Cents, so that $1000 \mathrm{ECU}$ are converted to 1.66 Euro. 


\subsection{Threshold strategies}

We examine the average number of subjects, whose behavior is consistent with an undominated threshold strategy for both treatments. The next table sums up the average number of subjects who played a threshold strategy, which was consistent with an undominated threshold strategy defined according to the five criteria: the mean of the two signals, the highest signal or the lowest signal.

\begin{tabular}{c|ccc|ccc}
\hline Information & \multicolumn{3}{|c|}{$P C S$} & \multicolumn{3}{c}{$T C S$} \\
\hline $\begin{array}{c}\text { No. of sessions } \\
\text { Definition of threshold }\end{array}$ & mean & high & low & mean & high & low \\
\hline R1 & 10.50 & 10.00 & 8.50 & 12.50 & 12.34 & 12.50 \\
R2 & 12.84 & 11.00 & 12.33 & 12.33 & 10.67 & 12.00 \\
R3 & 12.34 & 11.83 & 10.33 & 13.00 & 12.66 & 13.00 \\
R4 & 13.00 & 13.00 & 11.83 & 11.67 & 12.50 & 10.00 \\
R5 & 12.83 & 13.00 & 11.66 & 13.83 & 13.84 & 13.84 \\
R6 & 13.50 & 11.83 & 12.83 & 14.33 & 14.33 & 14.16 \\
R7 & 12.83 & 13.16 & 11.83 & 13.33 & 12.66 & 11.67 \\
R8 & 14.00 & 14.00 & 13.33 & 12.83 & 12.00 & 12.83 \\
R9 & 13.66 & 13.66 & 13.34 & 13.16 & 12.83 & 12.34 \\
R10 & 14.17 & 13.00 & 13.83 & 14.17 & 13.83 & 10.34 \\
R11 & 14.00 & 14.00 & 13.50 & 14.16 & 14.00 & 14.33 \\
R12 & 13.84 & 13.66 & 13.16 & 14.50 & 14.50 & 13.00 \\
R13 & 14.33 & 13.34 & 14.16 & 11.83 & 12.83 & 11.50 \\
R14 & 13.84 & 14.00 & 13.50 & 14.17 & 12.66 & 13.16 \\
R15 & 14.00 & 13.00 & 13.00 & 14.50 & 14.67 & 12.50 \\
R16 & 14.16 & 13.50 & 13.67 & 14.84 & 14.84 & 13.66 \\
Average & 13.36 & 12.90 & 12.55 & 13.46 & 13.20 & 12.57 \\
\hline
\end{tabular}

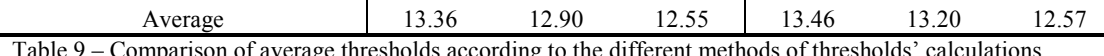

8.3. Logistic estimations and linear regressions

8.3.1. Variables used in linear regressions and logistic estimation

The next table explains the variables used for linear regressions and logistic estimation.

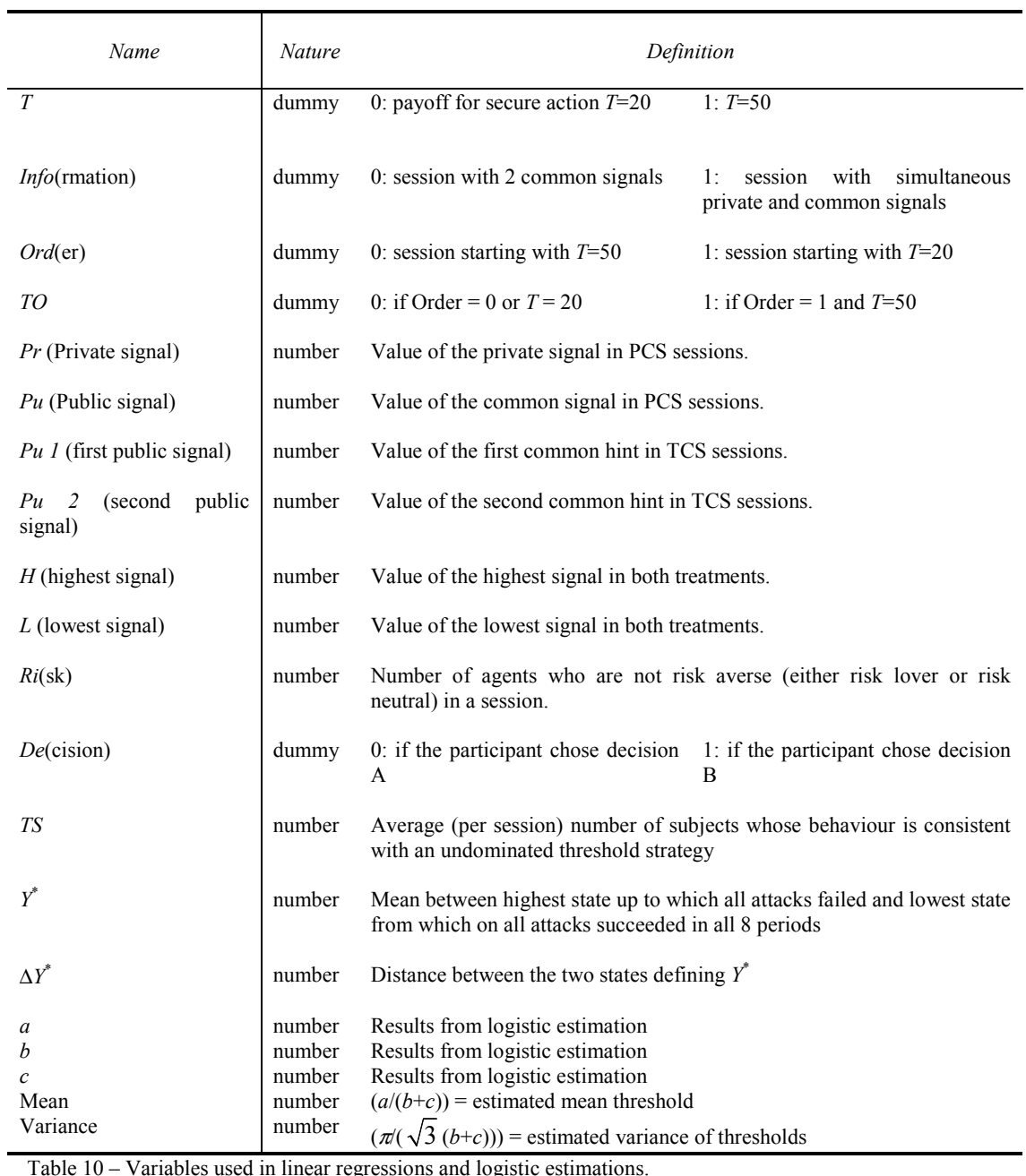


8.3.2. Logistic estimation

We use the following logit model:

$$
P(\mathrm{De})=\frac{1}{1+e^{-(\mathrm{De})}}
$$

where $D e=1$ if the participant chose decision $\mathrm{B}$ and 0 if the participant chose decision A. We assume that $D e$ is linearly related to the variables explained in the two cases below.

$D e_{i}=a+b P r+c P u+u$ for PCS sessions

or $D e_{i}=a+b P u 1+c P u 2+u$ for TCS sessions

where $u$ is the error.

The results of the logistic estimation are summed up in Table 11

\begin{tabular}{c|cccccc}
\hline$I$ & 2 & 3 & 4 & 5 & 6 & 7 \\
\hline Session & Infor- & Order & T & & Parameter estimation & \\
& mation & & & & & \\
& & & & a & $\mathrm{b}$ & $\mathrm{c}$ \\
30866249 & TCS & $20 / 50$ & 20 & 9.12 & 0.13 & 0.08 \\
30866249 & TCS & $20 / 50$ & 50 & 25.03 & 0.16 & 0.28 \\
34622802 & TCS & $20 / 50$ & 20 & 3.30 & 0.01 & 0.08 \\
34622802 & TCS & $20 / 50$ & 50 & 11.51 & 0.10 & 0.11 \\
49903521 & TCS & $20 / 50$ & 20 & 7.61 & 0.09 & 0.08 \\
49903521 & TCS & $20 / 50$ & 50 & 20.96 & 0.19 & 0.20 \\
27760776 & TCS & $50 / 20$ & 20 & 19.02 & 0.34 & 0.39 \\
27760776 & TCS & $50 / 20$ & 50 & 13.73 & 0.14 & 0.12 \\
35768884 & TCS & $50 / 20$ & 20 & 3.28 & 0.08 & 0.02 \\
35768884 & TCS & $50 / 20$ & 50 & 6.81 & 0.05 & 0.07 \\
50641587 & TCS & $50 / 20$ & 20 & 11.62 & 0.24 & 0.21 \\
5064587 & TCS & $50 / 20$ & 50 & 11.03 & 0.07 & 0.14 \\
29520578 & PCS & $20 / 50$ & 20 & 10.24 & 0.12 & 0.11 \\
29520578 & PCS & $20 / 50$ & 50 & 20.80 & 0.16 & 0.21 \\
28118404 & PCS & $20 / 50$ & 20 & 6.70 & 0.08 & 0.06 \\
28118404 & PCS & $20 / 50$ & 50 & 7.07 & 0.05 & 0.07 \\
37461307 & PCS & $20 / 50$ & 20 & 5.37 & 0.04 & 0.07 \\
37461307 & PCS & $20 / 50$ & 50 & 20.72 & 0.19 & 0.17 \\
37831221 & PCS & $50 / 20$ & 20 & 3.38 & 0.04 & 0.06 \\
37831221 & PCS & $50 / 20$ & 50 & 5.20 & 0.04 & 0.05 \\
53026879 & PCS & $50 / 20$ & 20 & 10.81 & 0.16 & 0.21 \\
53026879 & PCS & $50 / 20$ & 50 & 13.72 & 0.12 & 0.13 \\
53995310 & PCS & $50 / 20$ & 20 & 10.10 & 0.12 & 0.19 \\
53995310 & PCS & $50 / 20$ & 50 & 15.95 & 0.12 & 0.15 \\
\hline Table 11 - The first row is the session number. The next two rows give session specific conditions. Row 4
\end{tabular}

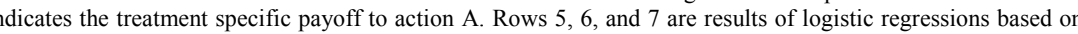
data of the last four periods of each treatment.
Owing to the data of Table 11, we calculate the estimated mean and standard deviation of individual thresholds. The results are summed up in Table 12 .

\begin{tabular}{|c|c|c|c|c|c|c|}
\hline 1 & 2 & 3 & 4 & 5 & 6 & 7 \\
\hline Session & $\begin{array}{l}\text { Infor- } \\
\text { mation }\end{array}$ & Order & $T$ & $\begin{array}{c}\text { Average } \\
\text { number of } \\
\text { "ratio- } \\
\text {-nal" } \\
\text { subjects }\end{array}$ & $\begin{array}{c}\text { Esti- } \\
\text { mated mean } \\
a /(b+c)\end{array}$ & $\begin{array}{c}\text { Esti- } \\
\text { mated standard } \\
\text { deviation } \\
\frac{\pi}{\sqrt{3}(b+c)}\end{array}$ \\
\hline 30866249 & TCS & $20 / 50$ & 20 & 13.37 & 43.43 & 8.64 \\
\hline 30866249 & TCS & $20 / 50$ & 50 & 14.87 & 56.88 & 4.12 \\
\hline 34622802 & TCS & $20 / 50$ & 20 & 12.50 & 36.67 & 20.15 \\
\hline 34622802 & TCS & $20 / 50$ & 50 & 13.12 & 54.81 & 8.64 \\
\hline 49903521 & TCS & $20 / 50$ & 20 & 13.12 & 42.28 & 10.08 \\
\hline 49903521 & TCS & $20 / 50$ & 50 & 14.12 & 53.74 & 4.65 \\
\hline 27760776 & TCS & $50 / 20$ & 20 & 14.00 & 26.05 & 2.48 \\
\hline 27760776 & TCS & $50 / 20$ & 50 & 12.62 & 52.81 & 6.98 \\
\hline 35768884 & TCS & $50 / 20$ & 20 & 13.87 & 32.80 & 18.14 \\
\hline 35768884 & TCS & $50 / 20$ & 50 & 13.00 & 56.75 & 15.11 \\
\hline 50641587 & TCS & $50 / 20$ & 20 & 13.50 & 23.23 & 0.22 \\
\hline 50641587 & TCS & $50 / 20$ & 50 & 13.25 & 51.96 & 1.44 \\
\hline 29520578 & PCS & $20 / 50$ & 20 & 12.37 & 44.52 & 7.89 \\
\hline 29520578 & PCS & $20 / 50$ & 50 & 14.62 & 56.22 & 4.90 \\
\hline 28118404 & PCS & $20 / 50$ & 20 & 12.50 & 47.85 & 12.96 \\
\hline 28118404 & PCS & $20 / 50$ & 50 & 13.00 & 58.92 & 15.11 \\
\hline 37461307 & PCS & $20 / 50$ & 20 & 12.25 & 48.82 & 16.49 \\
\hline 37461307 & PCS & $20 / 50$ & 50 & 14.37 & 57.56 & 5.04 \\
\hline 37831221 & PCS & $50 / 20$ & 20 & 12.75 & 33.80 & 18.14 \\
\hline 37831221 & PCS & $50 / 20$ & 50 & 11.62 & 57.78 & 20.15 \\
\hline 53026879 & PCS & $50 / 20$ & 20 & 14.87 & 29.22 & 4.90 \\
\hline 53026879 & PCS & $50 / 20$ & 50 & 13.75 & 54.88 & 7.26 \\
\hline 53995310 & PCS & $50 / 20$ & 20 & 14.37 & 32.58 & 5.85 \\
\hline 53995310 & PCS & $50 / 20$ & 50 & 13.87 & 59.07 & 6.72 \\
\hline
\end{tabular}

Table 12 - The first row is the session number. The next two rows give session specific conditions. Row 4 indicates the treatment specific payoff to action A. Row 5 gives the average number of subjects per period, whose behavior was consistent with undominated threshold strategies. Rows 6 shows the estimated mean of individual thresholds and row 7 the standard deviation of individual thresholds, calculated from estimates $a, b$ and $c$ in the previous table.
We define as "rational" behaviour any agent's behaviour, which is consistent with undominated threshold strategy defined by the mean of signals. 
8.3.3. Linear regressions

For all the linear regressions, we give the coefficient of the explanatory variable and in bracket the t-statistic.

Table 13 sums up the results from regressions $4,5,6,7,8,9$, and 10 , which determine the influence of the different explaining variables on the level of threshold.

Regression 4: $Y^{*}=\gamma_{0}+\gamma_{1} T+u$.

Regression 5: $Y^{\prime \prime}=\gamma_{0}+\gamma_{1} T+\gamma_{2}$ Info $+\gamma_{3}$ Ord $+\gamma_{4} T O+u$

Regressions 6-7: $Y=\gamma_{0}+\gamma_{1} T+\gamma_{3}$ Ord $+\gamma_{4} T O+u$.

Regression 8: $Y:=\gamma_{0}+\gamma_{1} R i+u$

Regressions 9-10: $Y^{*}=\gamma_{0}+\gamma_{1} T+\gamma_{2} R i+\gamma_{3} \operatorname{Ord}+\gamma_{4} T O+u$

\begin{tabular}{|c|c|c|c|c|c|c|c|c|}
\hline \multirow[t]{2}{*}{ No. } & $\begin{array}{l}\text { Data source } \\
\text { (number of } \\
\text { observations) }\end{array}$ & \multicolumn{6}{|c|}{$\begin{array}{c}\text { Explaining variables: estimated coefficients } \\
(t \text {-values })\end{array}$} & \multirow{2}{*}{$\begin{array}{c}R^{2} \\
\text { Adjusted } R^{2}\end{array}$} \\
\hline & & Intercept & $T$ & Info & Ord & TO & $R i$ & \\
\hline 4 & All treatments & 39.23 & 16.38 & & & & & 0.67 \\
\hline & (24) & (22.80) & $(6.73)$ & & & & & 0.66 \\
\hline 5 & & 30.96 & 21.57 & 3.59 & 12.94 & -10.37 & & 0.92 \\
\hline 6 & & $\begin{array}{l}(21.90) \\
35.58\end{array}$ & $\begin{array}{l}(12.06) \\
20.00\end{array}$ & (2.84) & $\begin{array}{l}(7.23) \\
13.04\end{array}$ & $\begin{array}{l}(-4.10) \\
-1153\end{array}$ & & $\begin{array}{l}0.91 \\
0.95\end{array}$ \\
\hline & $\begin{array}{l}\text { PCI } \\
(12)\end{array}$ & $(25.50)$ & $(10.13)$ & & $(6.61)$ & $(-4.13)$ & & 0.93 \\
\hline 7 & $\begin{array}{l}\text { Treatments with } \\
2 \mathrm{CS}(12)\end{array}$ & $\begin{aligned} 29.94 \\
(14.36)\end{aligned}$ & $\begin{array}{l}23.15 \\
(7.85)\end{array}$ & & $\begin{array}{l}12.83 \\
(4.35)\end{array}$ & $\begin{aligned}-9.21 \\
-2212\end{aligned}$ & & 0.92 \\
\hline 8 & $\begin{array}{l}2 \mathrm{CS}(12) \\
\text { All treatments }\end{array}$ & 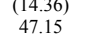 & $(7.85)$ & & $(4.35)$ & $(-2.21)$ & 0.03 & $\begin{array}{l}0.90 \\
0.00\end{array}$ \\
\hline & (24) & $(4.27)$ & & & & & & -0.04 \\
\hline 9 & $\begin{array}{l}\text { Treatments with } \\
\text { PCI }\end{array}$ & $\begin{array}{l}34.44 \\
(8.10)\end{array}$ & $\begin{array}{l}20.00 \\
(9.54)\end{array}$ & & $\begin{array}{l}13.07 \\
6.22\end{array}$ & $\begin{array}{l}-11.54 \\
(-3.89)\end{array}$ & $\begin{array}{l}0.10 \\
(0.29\end{array}$ & $\begin{array}{l}0.95 \\
092\end{array}$ \\
\hline & $\begin{array}{l}(12) \\
(12)\end{array}$ & & & & & & & \\
\hline 10 & $\begin{array}{l}\text { Treatments with } \\
\text { 2CS (12) }\end{array}$ & $\begin{array}{l}38.33 \\
(6.90)\end{array}$ & $\begin{array}{l}23.15 \\
(8.60)\end{array}$ & & $\begin{array}{l}13.12 \\
(4.86)\end{array}$ & 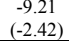 & $\begin{array}{c}-0.87 \\
(-1.61)\end{array}$ & $\begin{array}{l}0.95 \\
0.91\end{array}$ \\
\hline
\end{tabular}

Table 14 sums up the results of regressions $11,12,13,14$ and 15, which determine the influence of the different explanatory variables on the variation of thresholds.

Regression 11: $\Delta Y^{*}=\delta_{0}+\delta_{1} T+\delta_{2} \operatorname{Info}+\delta_{3} \mathrm{Ord}+\delta_{4} T O+u$

Regression 12: $\Delta Y^{*}=\delta_{0}+\delta_{2}$ Info $+u$

Regression 13: $\Delta Y^{*}=\gamma_{0}+\gamma_{1} R i+u$

Regressions 14-15: $\Delta Y^{*}=\gamma_{0}+\gamma_{1} T+\gamma_{2} R i+\gamma_{3} \operatorname{Ord}+\gamma_{4} T O+u$

\begin{tabular}{|c|c|c|c|c|c|c|c|c|}
\hline \multirow[t]{2}{*}{ No. } & \multirow{2}{*}{$\begin{array}{c}\text { Data source } \\
\text { (number of } \\
\text { observations) }\end{array}$} & \multicolumn{6}{|c|}{$\begin{array}{c}\text { Explaining variables: estimated coefficients } \delta_{i} \\
(t \text {-values })\end{array}$} & \multirow{5}{*}{$\begin{array}{c}R^{2} \\
\text { Adjusted } R^{2} \\
0.14 \\
-0.04 \\
0.10\end{array}$} \\
\hline & & Intercept & $T$ & & Ord & $T O$ & $\overline{R i}$ & \\
\hline 11 & All treatments & 11.81 & 0.33 & & -0.08 & 1.03 & & \\
\hline & & & & (1.52) & & & & \\
\hline & & $(1578)$ & & & & & & \\
\hline 13 & All treatments & 16.58 & & & & & -0.33 & 0.06 \\
\hline & & & & & & & $(-1.23)$ & \\
\hline & $\begin{array}{l}\text { Treatments with } \\
\text { PCI }\end{array}$ & $\begin{array}{l}\begin{array}{l}17.37 \\
(3.44)\end{array} \\
-\end{array}$ & $\begin{array}{l}-0,14 \\
(-0.05)\end{array}$ & & $\begin{array}{c}-2.33 \\
(-0.93)\end{array}$ & $\begin{array}{l}2.22 \\
(0.62)\end{array}$ & $\begin{array}{l}-0.25 \\
-0.59)\end{array}$ & 0.17 \\
\hline 15 & $\begin{array}{l}(12) \\
\text { Treatments with }\end{array}$ & & & & & & & \\
\hline & $2 \operatorname{CS}(12)$ & $(6.21)$ & $(0.49)$ & & (1.49) & $(-0.07)$ & $(-3.16)$ & 0.46 \\
\hline
\end{tabular}

Table 14 - Regressions explaining the width of the interval of indeterminate outcomes.
Table 15 sums up the results of regressions 16 and 17, which determine the influence of the different explanatory variables on the mean and variance of the probability of an attack.

Regression 16: $a /(b+c)=\alpha_{0}+\alpha_{1} T+\alpha_{2} \operatorname{Info}+\alpha_{3} \mathrm{Ord}+\alpha_{4} T O+u$

Regression 17: $\pi((b+c) \sqrt{3})=v_{0}+v_{1} T+v_{2} \operatorname{Info}+v_{3} \operatorname{Ord}+v_{4} T O+u$

\begin{tabular}{|c|c|c|c|c|c|c|c|}
\hline \multirow[t]{2}{*}{ No. } & \multirow{2}{*}{$\begin{array}{l}\text { Data source } \\
\text { (number of } \\
\text { observations) }\end{array}$} & \multicolumn{5}{|c|}{$\begin{array}{c}\text { Explaining variables: Coefficients } \\
(t \text {-values })\end{array}$} & \multirow{2}{*}{$\begin{array}{c}R^{2} \\
\text { Adj. } R^{2}\end{array}$} \\
\hline & & Intercept & $\begin{array}{l}T \\
\end{array}$ & Info & Ord & $T O$ & \\
\hline 16 & 24 & 27.54 & 25.9 & & & -13.50 & 0.95 \\
\hline 17 & 24 & $\begin{array}{c}(22.29) \\
7.26\end{array}$ & $\begin{array}{c}(16.59) \\
1.32\end{array}$ & $\begin{array}{l}(3.76) \\
2.06\end{array}$ & $\begin{array}{l}(9.16) \\
4.41\end{array}$ & $\begin{array}{l}(-6.11) \\
-6.96\end{array}$ & 0.15 \\
\hline
\end{tabular}

Table 15 - Linear regressions on estimated mean and variance thresholds. 